\title{
Saberes Psicológicos, Processos de Subjetivação e suas Implicações com a Biopolítica
}

\author{
Ana Cristina Sundfeld* \\ Universidade de São Paulo, São Paulo, SP, Brasil
}

\begin{abstract}
RESUMO
Este artigo discute a produção da psicologia como ciência nos parâmetros da racionalidade moderna e suas relações com a Biopolítica, sob a ótica do pensamento de Foucault, considerando que os discursos psicológicos operam como estratégias de controle, de normalização e de apoio a determinadas formas de subjetivação. Reflete sobre os efeitos dos saberes psicológicos nos processos de subjetivação na contemporaneidade, em sua relação com a medicalização e busca possibilidades de novas proposições para a psicologia. Ressalta que para potencializar modos de intervenção libertadores e favoráveis à produção de um sujeito ativo no plano da formação profissional é imprescindível a análise da fabricação da psicologia como ciência e do estabelecimento de noções como sujeito, saúde, sofrimento, intervenções e formas de cuidado e seus efeitos. Importa salientar que pessoas que se afetam pela presença do outro e no encontro movem diferentes sentidos e lógicas, ao invés de apenas reproduzirem técnicas que operam sobre o outro. Na escuta do imprevisível, estes profissionais se colocam em abertura aos processos de subjetivação disparados nos encontros.
\end{abstract}

Palavras-chave: saberes psicológicos; biopolítica; processos de subjetivação; medicalização.

\section{ABSTRACT \\ Psychological Knowledge, Production of Subjectivity and Implications with the Bio-Politics}

This article discusses the production of psychology as a science in parameters of modern rationality and it examine its relationship with biopolitics, thinking with Foucault that psychological discourses can operate as control strategies, standardization and support to certain forms of subjectivity. It reflects about the effects of psychological knowledge in the processes of subjectivity in contemporary world and the practices of the medicalization. Moreover, it search to present new propositions and possibilities for psychology. Points out that to enhance liberators procedures for intervention and favorable to the production of an active subject in the vocational training plan is essential to analyze the psychology of manufacturing and science and the establishment of notions such as subject, health, pain, interventions and forms of care and their effects. It should be noted that people who are affected by the presence of the other and move in different directions meet and logical, rather than just reproducing techniques which operate on the other. In listening to the unpredictable, these professionals put themselves in openness to subjectivity elicited processes in meetings.

Keywords: psychological knowledge; bio-politics; production of subjectivity; medicalization.

De acordo com Foucault (1990), desde o final do século XVIII a vida individual e coletiva emergiu como objeto de preocupação do Estado, inspirando políticas, estratégias de controle, intervenções e novos saberes. O biopoder se refere à gestão da vida, apoiado em saberes e práticas destinadas a regular, normalizar, otimizar, criar uma forma-homem ou modos padronizados de existência. Opera a partir de uma dupla face:

[...] por um lado as disciplinas, as regulações, a anátomo-política do corpo, por outro a biopolítica da população, a espécie, as performances do corpo, os processos da vida - é o modo que tem o poder de investir a vida de ponta a ponta. [...] Se as disciplinas se dirigiam ao corpo, ao homem-corpo, a biopolítica 
se dirige ao homem vivo, ao homem- espécie. (Pelbart, 2009, p. 11)

Os saberes sobre a saúde se produziram neste campo permeado pelos interesses do biopoder e da racionalidade científica moderna, em embate com outras forças e racionalidades.

Elemento fundamental para o desenvolvimento do capitalismo, os processos da vida são inseridos no campo das técnicas políticas de tal modo que: "o fato de viver não é mais esse sustentáculo inacessível que só emerge de tempos em tempos, no acaso da morte e de sua fatalidade; cai, em parte, no campo de controle do saber e de intervenção do poder" (Foucault, 1990, p. 134). Consequentemente a vida é investida por mecanismos de regulação que vão atuar sobre o corpo, a saúde, a alimentação, estendendo-se a todas as esferas da existência.

Variados saberes contribuíram para a produção de discursos sobre o sujeito com vistas à sua individualização, controle e normalização. Em meados do século XIX, a psicologia é legitimada como disciplina científica e mais do que a produção de novos conhecimentos sobre o homem, esse saber produziu algo como um modelo de indivíduo.

A legitimação de uma disciplina no campo da ciência pressupõe a definição de um objeto; esta condição impulsiona, no plano da psicologia, a construção de um homem universal, a-histórico, atemporal, determinado em seus aspectos essenciais pelo saber psicológico. Decorre que esta imagem de homem abstrato, descolado das tensões imanentes ao viver e aos processos de subjetivação, contribuiu para a fabricação de noções sobre saúde e doença, ou melhor, sobre normalidade e loucura, consideradas fenômenos naturais pelo discurso da ciência dominante.

A definição de normalidade tornou-se fundamental na construção da psicologia científica. A formação deste conceito relaciona-se à constituição da medicina no século XIX. Até este século, a medicina concebia a saúde e a doença como de natureza absolutamente distintas: "A saúde e a doença disputavam o homem, assim como o Bem e o Mal disputavam o mundo" (Canguilhem, 1990, p. 77). Com a medicina moderna, saúde e doença são redefinidas e vistas como aspectos inerentes à própria vida: "Trata-se de uma tese segundo a qual os fenômenos patológicos são idênticos aos fenômenos normais correspondentes, salvo pelas variações quantitativas" (Canguilhem, 1990, p. 17). A igualdade e a continuidade que se estabelecem entre $\mathrm{o}$ normal e o patológico implicam numa definição da norma a partir da qual se reconhece o patológico através de sua variação, através do seu desvio.

O parâmetro que define o limiar entre o normal e o patológico é quantitativo, ou seja, a diferença é avaliada pela estatística e classificada segunda uma distinção de frequência. Estas representações afetam a produção da psicologia, resultando na construção de dois tipos de discursos: o da psicologia normal que legitimou um padrão comum de comportamento e o da psicologia patológica que enquadrou as variações em categorias, ambas complementares para a fabricação do sujeito psicológico. Vale destacar que a possibilidade da psicologia decorre de uma análise psicológica da loucura: "Não se deve esquecer que a psicologia 'objetiva', 'positiva' ou 'científica' encontrou sua origem histórica e seu fundamento numa experiência patológica" (Foucault, 2000, p.84).

O sujeito psicológico, correlato de um "eu" interior, possível de ser desvendado, ganha contornos científicos via experiência "patológica" da desmesura, do descontrole, das paixões. É a interiorização da loucura que torna o homem psicologizável, ou seja, o constitui como objeto que possibilita a psicologia científica: "pode-se dizer que a psicologia contemporânea é, em sua origem, uma análise do anormal, do patológico, do conflituoso, uma reflexão sobre as contradições do homem consigo mesmo" (Foucault, 1999, p. 123).

O homo psychologicus emergiu como produção no interior de um discurso psiquiátrico articulado à medicina moral que contribuiu para a fabricação de personagens como o louco, o delinquente, o perverso, o neurótico, dentre outros. As variações foram nomeadas, classificadas e ordenadas por um conjunto de tecnologias que instituíram o desejável ou indesejável para a consolidação de uma certa sociedade. Neste sentido, os saberes psicológicos contribuíram como um poderoso instrumento de modelização de comportamentos e valores. Sem dúvida, este homem psicologizável tornou-se igualmente regulável e adaptável.

Daí a importância de colocarmos incessantemente em análise teorias e práticas, pois a psicologia, como todo saber, longe de ser constituída por especialistas que estariam problematizando a realidade objetivamente, num plano transcendente e descolado de implicações ético-políticas, opera na fabricação de processos de subjetivação e modos de vida. Trata-se, portanto, de um campo povoado por racionalidades em disputa, que traduzem diferentes modos de pensar, intervir e se implicar. 
Os discursos psicológicos, em sua maioria, apoiam-se em dicotomias como consciente-inconsciente, sujeito-objeto, interior-exterior, indivíduo-sociedade, neutralidade-envolvimento, mente-corpo. Além disso, geralmente privilegiam um modelo psíquico universalizante, fortemente representado por perspectivas de desenvolvimento humano que modulam a saúde do sujeito e desenham as margens e os limites de transgressões possíveis, desvinculado do contexto socialcultural-político no qual os sujeitos se situam. Embora gradativamente questionado, este modelo abstrato muitas vezes povoa as práticas dos profissionais, que (re)produzem formas hegemônicas de amar, pensar, desejar e viver. Preso a estas dicotomias, o profissional atua a partir de um plano transcendente, limitado por representações artificialmente construídas que fundamentam procedimentos, técnicas e ideais de subjetivação.

Ora, este modelo psíquico universalizante desconsidera a perspectiva da subjetividade como produto imanente ao tecido social e histórico, fabricada e modelada num plano de forças dinâmico, no qual agenciamentos ocorrem, compondo, num movimento de (des)construção, paisagens subjetivas. Ademais, o indivíduo consciente - esse que aparece em alguns discursos psi como produção de um sujeito que define a realidade e constitui a si mesmo - é uma ficção que fortalece os dualismos e polaridades que situam, por exemplo, o indivíduo de um lado e o social do outro. No entanto, com Deleuze e Guattari (2000), podemos dizer que "não existe enunciado individual, nunca há. Todo enunciado é o produto de um agenciamento maquínico, quer dizer, de agentes coletivos de enunciação" (p. 51).

Este eu é, portanto, constituído, modelado, inventado, a partir de uma orquestração de vozes diversas que incessantemente desmancham qualquer paisagem identitária. Consideramos que os processos de subjetivação correspondem à produção de novas paisagens, deslocamento e movimento, afirmação e desejo de diferença, portanto, impossível de qualquer totalização. O desejo de definir o homem, negando a transitoriedade que o atravessa, reflete um movimento de dominação tendente a minimizar a diferenciação produtiva que pulsa nos processos de subjetivação.

É do complexo jogo de forças, composto de aspectos sociais, culturais, políticos, históricos, econômicos, que a subjetividade é tecida. Os comportamentos, valores, modos de relação e estilos de consumo que compõem a subjetividade são produzidos no campo do social (Guattari \& Rolnik, 2000). Nele, os discursos referentes aos modos de subjetivação são legitimados através de dispositivos de poder e saber que os consideram discursos verdadeiros. Em outras palavras, as verdades do discurso são produzidas e exercem um papel regulador nas existências dos indivíduos:

Cada sociedade tem seu regime de verdade, sua ' política geral' de verdade: isto é, os tipos de discurso que ela acolhe e faz funcionar como verdadeiros; os mecanismos e instâncias que permitem distinguir os enunciados verdadeiros dos falsos, a maneira como se sanciona uns e outros; as técnicas e os procedimentos que são valorizados para a obtenção da verdade; o estatuto daqueles que têm o encargo de dizer o que funciona como verdadeiro. (Foucault, 2006, p. 12)

Neste sentido, os discursos habitam o território da ética, pois mobilizam formas de viver, de desejar, de pensar, seja a favor da liberdade do indivíduo e da afirmação da diferença, seja a favor de um modo de ser submisso e escravo, obediente às formas aprisionadoras e pré-estabelecidas.

\section{MEDICALIZAÇÃO DA EXISTÊNCIA E PROCESSOS DE SUBJETIVAÇÃO}

Na sociedade contemporânea assistimos ao recrudescimento da produção de regimes de verdade que regulam gestos, pensamentos, sentimentos, escolhas, desejos e modos de vida. Tudo o que concerne ao homem e sua existência é posto sob um olhar avaliador, supostamente neutro, porém repleto de normas, valores e preconceitos que nada têm de imparcialidade, senão que comunicam uma aversão à diversidade $\mathrm{e}$ à liberdade.

Foucault criou o termo biopolítica para expressar a política sobre a vida, a gestão e a governança da vida do indivíduo e das populações na modernidade:

[a biopolítica] é contemporânea do aparecimento e da proliferação das categorias de anormalidade - o delinquente, o perverso, etc., do par normal-anormal, que as tecnologias do biopoder e os saberes investidos nestas tecnologias supostamente, no limite, eliminariam. Ao identificar cientificamente as anormalidades, as tecnologias da biopolítica estariam numa posição perfeita para supervisioná-las e eliminá-las. (Portocarrero, 2008, p. 421)

A medicalização relaciona-se com a biopolítica. Neste sentido, estamos num campo de combate ao que escapa da média, da norma, suposta transgressão. Em caso de suspeita, qualquer expressão avaliada como 
transgressora é rapidamente conduzida à tutela do saber médico. Atualmente quando apelamos para um discurso exterior ao domínio médico, vemos sua captura por outro discurso também relacionado à perspectiva médica. Vivemos a proliferação de uma cultura da medicalização que se espraia nas escolas, nos espaços de trabalho, na família, fabricando consumidores de diagnósticos e tratamentos, inclusive psicoterapêuticos.

Nas escolas é frequente o discurso normalizador que tende à produção serializada de alunos-problema, inadequados e indesejados. Nestes casos, a psicologia e a psiquiatria são convocadas como saberes capazes de identificar, nomear, tratar e curar os desvios de uma dada normalidade. A força deste dispositivocontrole é intensa no interior das escolas, como exemplifica a ilustração seguinte que relata uma experiência de estágio em Plantão Psicológico em escolas públicas da cidade de São Paulo, do ensino infantil ao ensino médio, ancorada na perspectiva fenomenológico-existencial. O Plantão Psicológico é uma modalidade de atendimento que compõe a disciplina Práticas Psicológicas, ofertada pela Universidade Paulista UNIP para os alunos do último ano do curso de graduação em Psicologia.

A proposta do plantão foi oferecer uma escuta à demanda imediata dos alunos, no intuito de fabricar, em parceria, alternativas e projetos de vida. Tratava-se de uma sessão e até dois retornos, cuja aposta focava o movimento, a criação de possibilidades de saúde. Cada encontro era compreendido como um campo aberto para invenções, valorizado em sua potência transformadora e resignificadora de experiências.

Durante o primeiro semestre de 2012, os estagiários do curso de Psicologia foram distribuídos em um Centro de Educação Infantil (CEI), um Centro de Ensino Unificado (CEU) e uma Escola Estadual, localizados na zona leste da cidade. Uma característica do plantão psicológico é a busca espontânea do usuário. Observamos, no entanto, que as escolas produziram novos fluxos, pois os alunos e/ou responsáveis eram encaminhados em sua maioria pela coordenação pedagógica. Houve, portanto, um movimento de captura institucional dos sentidos do plantão, re-situado como espaço de orientação e correção de comportamentos indesejáveis. Deste modo, as demandas encaminhadas eram: agressividade, agitação, mau comportamento, rebeldia, longa permanência diária na instituição e supostos efeitos, etc. Os alunos e/ou responsáveis geralmente manifestavam surpresa pelos encaminhamentos, alguns discordavam dos "supostos" motivos do mesmo, outros atendiam ao pedido da coordenação passivamente.

No primeiro contato com a proposta de estágio, a diretora do CEU, por exemplo, fez questão de afirmar: "quero passar todas as minhas crianças", ao que parece uma medida preventiva em tempos da propagada gestão dos riscos na saúde que cria uma necessidade de encaminhamento indiscriminado para os especialistas. Apesar das insistentes conversas com a mesma no intuito de problematizar a atividade do plantão na escola, a prática do encaminhamento continuou operando, em menor quantidade, porém seguindo a mesma lógica de psicologização e busca de "tratamento" para o sujeito-problema.

Em outras palavras, na maioria dos casos o plantão psicológico foi visto pelas escolas como uma solução medicalizante, capaz de combater os comportamentos "indesejáveis" dos alunos.

Na prática, buscamos abordar o aluno e/ou responsável a respeito das suas perspectivas sobre o plantão e a atuação do psicólogo; alguns manifestavam desconhecimento e durante a conversa afirmavam que não percebiam a necessidade do atendimento. $\mathrm{O}$ estágio oportunizou reflexões e possibilidades de reinvenção do lugar do psicólogo na visão dos usuários assim como a problematização e a desconstrução de supostas demandas.

Outro exemplo ilustrativo da tendência à medicalização da vida é a versão atual do DSM (Manual de Estatísticas de Diagnósticos) da Associação de Psiquiatria Americana, lançado recentemente (Biderman, 2013). Nele encontramos novas categorias diagnósticas como, por exemplo, "desregulagem perturbadora do humor", cujos critérios para diagnosticar pessoas entre seis e 18 anos são "acessos de raiva com intensidade ou duração muito desproporcional à situação"; outra nova "doença" é a compulsão alimentar, que já era reconhecida como sintoma de transtornos alimentares, mas agora é reconhecida como distúrbio por si e significa ter pelo menos 12 episódios de comilança em um período de três meses.

A construção crescente de novos diagnósticos patologiza expressões de raiva, gulodice, tristeza e outras tantas que povoam o cotidiano. Assim, comportamentos tornam-se suspeitos, crianças e jovens são 
conduzidos aos especialistas e logo se transformam em consumidores de medicamentos.

A neurociência e a indústria farmacêutica funcionam como produtores de regimes de verdade que exercem forte pressão no campo de disputa que regula o saber-fazer em saúde. Seus discursos participam da produção das demandas dos usuários, legitimam práticas dos profissionais e influenciam diretamente a construção das políticas públicas.

A medicalização dispara processos de subjetivação que resultam em sujeitos padronizados, cuja vida é incessantemente empobrecida de variações e experimentações. Ademais, modos de vida são postos sob tutela de especialistas e outras tecnologias de invenção/administração do eu que comandam a fabricação de uma subjetividade serializada. Convivemos numa sociedade intolerante à diferença, cujas expressões de singularidade são rapidamente capturadas e recodificadas de acordo com interesses econômicos ávidos pela produção de novos produtos e consumidores:

O capitalismo transforma o não-capital em capital, não só paisagens, ritmos, mas também maneiras de ser, de fazer, de ter prazer, atitudes, e nisso consiste sua inventividade nos últimos anos, na intuição de antecipar os desejos do público, com a importância crescente dos investimentos culturais e tecnológicos. Mercantilização da diferença, da originalidade que, claro, logo se perde -, de um novo sentido, que também se esvai, gerando novas formas de inquietude e talvez novos limites. (Pelbart, 2009, p. 23)

Vemos, portanto, um forte investimento na produção de processos de subjetivação que opera nos espaços sociais e é atravessado por diversos saberes. A psicologia, cujo território é múltiplo e habitado por racionalidades distintas, participa ativamente da invenção de sujeitos e modos de vida. Por isso, reconhecer as relações deste campo com a biopolítica abre possibilidades de crítica sobre seus discursos e práticas, traçando para o pensamento e para a sensibilidade caminhos de resistência à decodificação e à sujeição da vida no interior deste saber-fazer, vida que escapa incessantemente às técnicas de controle, dado que "não há relações de poder sem resistências; [...] estas são tão mais reais e eficazes quanto mais se formem ali mesmo onde se exercem as relações de poder (Foucault, 2003, p. 249)".

\section{OUTRAS TRILHAS POSSÍVEIS PARA A PSICOLOGIA?}

A renovação radical da psicologia como ciência do homem não é, portanto, simplesmente um fato histórico do qual podemos situar o desenrolar durante os últimos cem anos; ela ainda é uma tarefa incompleta a ser preenchida e, a esse título, permanece na ordem do dia. (Foucault, 1999, p. 123)

Os discursos psicológicos circulam no universo social, produzem cenas, tecem narrativas sobre o viver, implicam a produção de certos modos de amar, pensar, trabalhar, ser. A problematização da psicologia e de seus efeitos é fundamental, sobretudo no contexto da sociedade contemporânea cujo forte investimento do capital se dá na produção de processos de subjetivação:

A subjetividade capitalística, tal como é engendrada por operadores de qualquer natureza ou tamanho, está manufaturada de modo a premunir a existência contra toda intrusão de acontecimentos suscetíveis de atrapalhar e perturbar a opinião. Para esse tipo de subjetividade, toda singularidade deveria ou ser evitada, ou passar pelo crivo de aparelhos e quadros de referência especializados. Assim, a subjetividade capitalística se esforça por gerar o mundo da infância, do amor, da arte, bem como tudo o que é da ordem da angústia, da loucura, da dor, da morte, do sentimento de estar perdido no cosmos... (Guattari, 2006, p. 33)

Como produzir outras referências e diálogos para a psicologia? Como criar contágio, fazer crescer entre os profissionais uma reflexão radical, aberta a desconstrução e invenção de novas paisagens? Tais movimentos se apoiam na recusa aos ideais de verdade e de imparcialidade, pois implicados com a invenção ético-política do mundo, operam na criação de territórios existenciais.

A ampliação do espaço da psicologia no modelo de atenção à saúde pública pode contribuir para a crítica e desconstrução dos artifícios teórico-técnicos consolidados nas práticas e, neste sentido, o arsenal psicológico torna-se objeto de análise. Com efeito, as reformas no modelo de atenção à saúde com as políticas de saúde mental e de atenção básica, por exemplo, ampliaram a inserção de psicólogos nos equipamentos de saúde.

Neste contexto a saúde pública interroga as práticas psicológicas, suscitando incômodos e questionamentos que podem tornar-se potentes para sua desa- 
comodação. O que podem suas intervenções? O que produzem em termos de processos de subjetivação? Como provocar rupturas com o modelo de individualização dominante nos discursos psicológicos e inserir diferentemente o pensamento num plano de articulação com as forças sociopolíticas que o atravessam? Como potencializar modos de intervenção libertadores e favoráveis à produção de um sujeito ativo, ao invés de reproduzir uma prática corretiva e uniformizante?

No plano da formação profissional há de se realizar transformações urgentes que assegurem o pensamento crítico, contestatório, reflexivo e criativo. É imprescindível a análise da fabricação da psicologia como ciência e do estabelecimento de noções como sujeito, saúde, sofrimento, intervenções e formas de cuidado e seus efeitos. Isto porque, forjada a partir dos parâmetros científicos, a história da ciência psicológica foi esvaziada dos atravessamentos culturais, políticos, das produções mutantes de subjetivação e da dimensão do poder, elementos implicados no espaço social que lhes deu origem. Um dos efeitos desta lógica em seus discursos e práticas é a redução da complexidade do sujeito ao domínio psicológico de um eu privado e abstraído das forças do Fora.

Ora, uma formação que insiste na fragmentação dos saberes impossibilita o diálogo entre as disciplinas, empobrecendo o pensamento e naturalizando falsas segmentações entre os planos social, psíquico, econômico, cultural e político. Este modo de pensar desprovido de ferramentas críticas contribui para a crescente medicalização do sofrimento, a produção de prescrições e cartilhas para uma vida saudável aliada a intensificação de valores ditados pela globalização capitalística.

Apostamos, entretanto, na construção de anômalos que fogem às regras de formação postas pela grande maioria das instituições de ensino. Pessoas que se afetam pela presença do outro e no encontro movem diferentes sentidos e lógicas, ao invés de apenas reproduzirem técnicas que operam sobre o outro. Na escuta do imprevisível, estes profissionais se colocam em abertura aos processos de subjetivação disparados nos encontros, em si e no outro, atentos aos riscos de engessamento e de recusa à diferença, produzindo em oposição a estes, espaços de liberdade e de linhas de fuga:

[...] mirar o que são os "outros" em cada um de nós e para nós [...]. Pode-se assim fazer escolhas de vozes, de capturas e de liberdades, pode-se escolher alguns territórios de implicações, pode-se, entre tantas possibilidades, escolher algumas que nos encarnam: apostar na produção da vida de modo solidário ou solitário. (Merhy, 2010, p. 36)

\section{REFERÊNCIAS}

Biderman, I. (2013, maio 21). Médica americana explica seu apoio à nova 'bíblia' da psiquiatria. Folha de S. Paulo. Retirado em junho 24, 2013, de http://acervo.folha.com.br/fsp/2013/05/21/15/

Canguilhem, G. (1990). O normal e o patológico ( $3^{\mathrm{a}}$ ed. rev. e aumentada). Rio de Janeiro: Forense Universitária.

Deleuze, G. \& Guattari, F. (2000). Mil platôs (Vol. 1, $2^{\mathrm{a}}$ ed.). São Paulo: Editora 34.

Foucault, M. (1990). Direito de morte e poder sobre a vida. Em M. Foucault. História da sexualidade I - A vontade de saber (pp. 127-149). Rio de Janeiro: Editora Graal.

Foucault, M. (1999). A psicologia de 1850 a 1950. In: M. Foucault. Problematização do sujeito: psicologia, psiquiatria e psicanálise (pp. 122-139). (Coleção Ditos e Escritos I). Rio de Janeiro: Forense Universitária.

Foucault, M. (2000). Doença mental e psicologia (6 ${ }^{\mathrm{a}}$ ed.). Rio de Janeiro: Tempo Brasileiro.

Foucault, M. (2003). Poderes e estratégias. Em M. Foucault. Estratégia, poder-saber (pp. 241-252). (Coleção Ditos e Escritos IV). Rio de Janeiro: Forense Universitária.

Foucault, M. (2006). Microfísica do poder (22 ${ }^{\mathrm{a}}$ ed.). Rio de Janeiro: Ed. Graal.

Guattari, F. (2006). As três ecologias (17 ed.). Campinas, SP: Papirus.

Guattari, F. \& Rolnik, S. (2000). Micropolítica: cartografias do deseo. Petrópolis/RJ: Ed. Vozes.

Merhy, E. (2010). Desafios de desaprendizagens no trabalho em saúde: em busca de anômalos. Em A. M. Lobosque (Org). Seminário Saúde Mental: os desafios da formação. (Vol. 3, pp. 23-36). Belo Horizonte: ESP - MG.

Pelbart, P. P. (2009). Vida capital: Ensaios de biopolítica. São Paulo: Iluminuras.

Portocarrero, V. (2008). Os limites da vida: da biopolítica aos cuidados de si. Em D. M. Albuquerque Jr., A. VeigaNeto \& A. de Souza Filho (Orgs.), Cartografias de Foucault (pp. 419-430). Belo Horizonte: Autêntica Editora.

Recebido em: 23/09/2013

Última Revisão em: 31/10/2014 Aceito em: 10/07/2015 